\title{
The Effect of Adding Halloysite Nanotubes as Filler on the Mechanical Properties of Low-Density Polyethylene
}

\author{
L'udmila Dulebová ${ }^{1, a^{*}}$, Karolina Glogowska ${ }^{2, b}$, Jaroslav Hájek ${ }^{3, c}$ \\ and Jakub $\mathrm{Fic}^{4, \mathrm{~d}}$
}

\author{
${ }^{1}$ Technical University of Košice, Faculty of Mechanical Engineering, Department of Automobile \\ Production, Mäsiarska 74, 04001 Košice, Slovakia \\ ${ }^{2}$ Lublin University of Technology, Department of Technology and Polymer processing, \\ 36 Nadbystrzycka St., 20-618 Lublin, Poland \\ ${ }^{3}$ Borra s.r.o., Praha, Czech Republic \\ ${ }^{4}$ Zamak Mercator sp. z o.o., Skawina, Poland \\ aludmila.dulebova@tuke.sk, bk.glogowska@pollub.pl, chajek@borra.cz, djfic@zamakmercator.pl
}

Keywords: injection molding, Low-Density Polyethylene, Halloysite nanotubes, tensile strength, hardness, impact strength

\begin{abstract}
Reinforcing thermoplastic polymers with nanotubes or nanoplatelets to form nanocomposites is a way to increase the usage of polymeric materials in engineering applications by improving their mechanical properties. The contribution presents the results of research from basic processing and mechanical properties of nanocomposites. Low-Density Polyethylene (LDPE) was used as a matrix for experiments. The material LDPE was modified by Halloysite nanotubes (HNT) with a mass share of $2,4,6 \mathrm{wt} \%$ of the matrix LDPE. Nanocomposites were filled with $5 \mathrm{wt} \%$ Polyethylene grafted with maleic anhydride (PE-graft-MA) as a compatibility factor. The specimens were prepared by injection molding and their selected mechanical properties were tested by static tensile test, Charpy impact test and Shore hardness test.
\end{abstract}

\section{Introduction}

Nanocomposites are a new class of composites that are particle-filled composites in which at least one dimension of the dispersed particles is in the nanometer range. One of the interesting aspects of the use of nanofillers is the low concentration of that filler that needs to be added to the polymer system to obtain desired property improvements $[1,2]$.

Nanotechnology is a rapidly growing interdisciplinary field of knowledge, spanning many areas of research. There are always critical needs for lighter, stronger, less expensive, and more versatile materials to meet the demands of industrial consumers. The synthesis of polymer nanocomposite is an integral aspect of polymer nanotechnology. Polymer nanocomposite has been known as one of the early success stories of realizing the potential of nanomaterial as reinforcement filler to improve the properties of neat polymers. By adding the nano sized organic compounds, the properties of polymers are improved $[3,4,5]$. Properties of the nanocomposites produced are depending on the inorganic materials present in the polymers matrix [6].Reinforcing thermoplastic polymers with nanoparticles to form nanocomposites is a way to increase the usage of polymeric materials in engineering applications by improving their mechanical properties, namely elastic modulus and yield stress with filler contents as low as $5-10 \mathrm{wt} \%[7,8,9]$. There are different types of commercially available nanoparticles that can be incorporated into the polymer matrix to form polymer nanocomposites $[10,11]$.

Nanocomposites are possible to sort by geometric shape of reinforcement to (Fig 1):

- Nanoparticle-reinforced composite $\left(\mathrm{CaCO}_{3}, \mathrm{TiO}_{2}, \mathrm{SiO}_{2} \ldots\right)$,

- Nanofibre-reinforced composite (carbon nanotubes - CNT, halloysite - HNT),

- Nanoplateled-reinforced composite (organically modified clay, expanded graphite). 


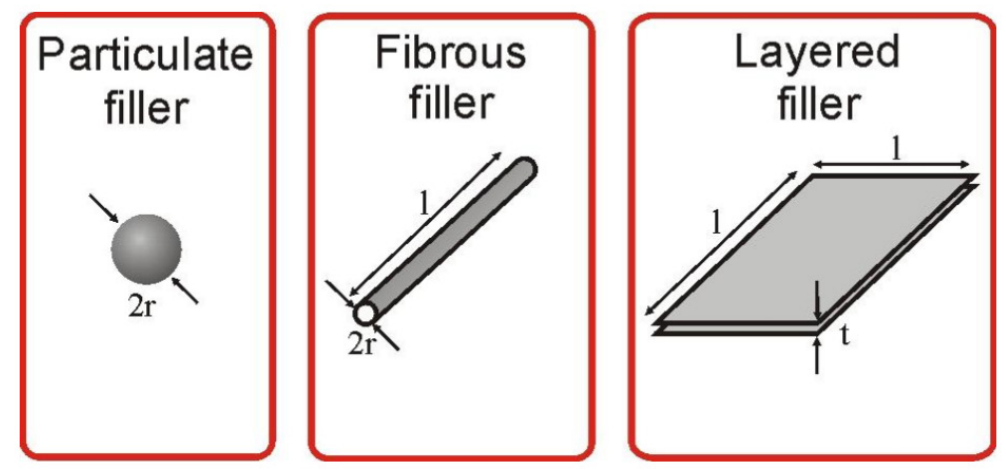

Fig. 1 Geometric shape of reinforcement

Thermoplastic/HNT nanocomposites exhibit markedly increased storage modules and flexural strength. The positive effects of the HNTs on the performance of the polymeric matrix are correlated with the unique characteristics of the HNTs, the uniform dispersion and the possible interfacial reactions between the modified HNTs and the matrix. The existing literature suggests that that these nanocomposites possess excellent performance including reinforcing effects, enhanced flame retardancy and reduced thermal expansion [12].

\section{Experimental}

The article aims to investigate the influence of filler content halloysite nanotubes (HNT) on the selected mechanical properties of polymer nanocomposites with LDPE matrix. Nanocomposites were filled with $5 \mathrm{wt} \%$ Polyethylene grafted with maleic anhydride (PE-graft-MA) as a compatibility factor.

\section{Production of specimens}

The specimens for testing were production by injection molding on injection molding machine type Arburg Allrounder 320 C $500-170$. View of injection mould with cavities in the form of the specimens for static tensile tests is presented in Fig.2. The cavity has a shape of paddles testing and the following dimensions: length $L_{1}=150 \mathrm{~mm}$, a width of from $b_{2}$ to $b_{1}=10=20 \mathrm{~mm}$, depth $\mathrm{a}=4 \mathrm{~mm}$.
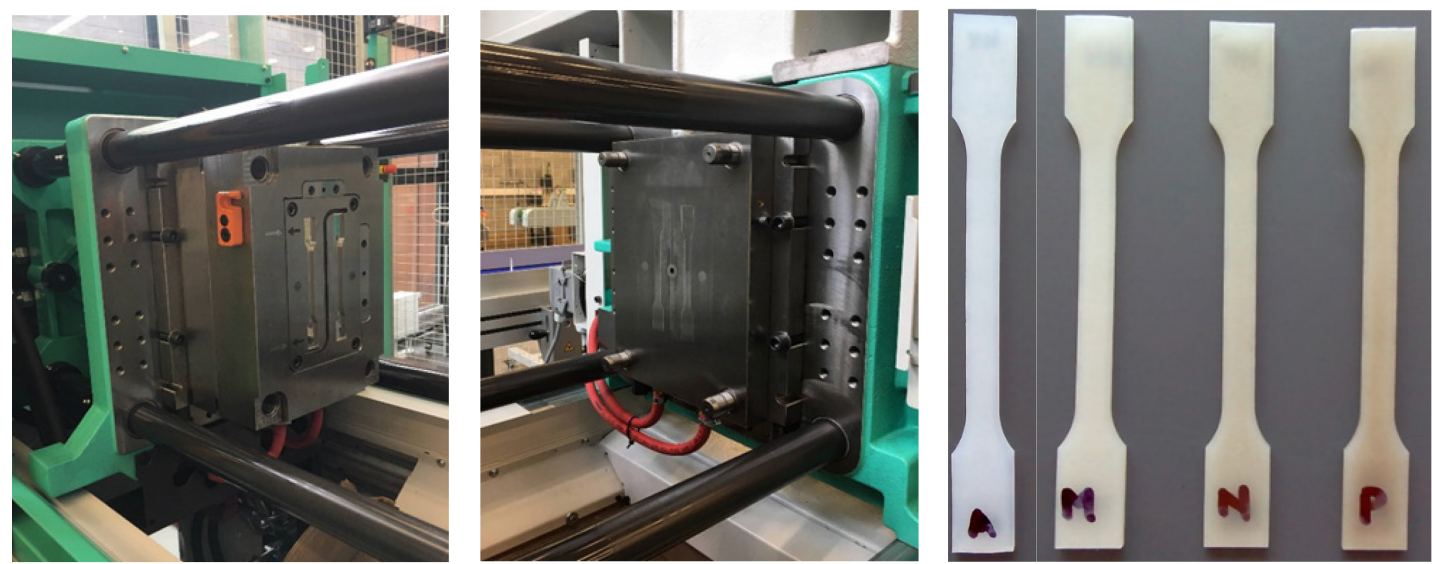

Fig. 2 View of injection mould with cavities in the form of the specimens for tensile tests and the specimens for tensile test of LDPE material with various \% HNT and 5\% PE-graft-MA:

A- LDPE; M- LDPE/2\%HNT; N- LDPE/4\% HNT; P- LDPE/6\% HNT

The injection process of the polymer nanocomposites were performed under the following conditions:

- the temperature of the heating zones of the plasticizing system of the injection moulding machine, starting with the hopper, equalled $100,140,160,170$ and $180^{\circ} \mathrm{C}$,

- the temperature in the feed opening zone was set at $30{ }^{\circ} \mathrm{C}$, 
- the total time of the injection process cycle equalled 34.16 second, including the cooling time of 20 second,

- injection pressure: $100 \mathrm{MPa}$,

- the holding pressure equalled $85 \mathrm{MPa}$,

- the temperature of the injection mould was set at $18{ }^{\circ} \mathrm{C}$.

\section{Materials for experiments}

The polymer used in the experimental tests was Low- Density Polyethylene (LDPE) marketed under the trade name Malen E and symbol FGAN 18-D003, produced by Basell Orlen Polyolefins Company. Linear low density polyethylene (LLDPE) is an important thermoplastic for the applications such as electric wire, cable, film, pipe and container [13]. However, its applications are limited, especially due to its relatively low strength, low softening point and flammability resistance. Therefore, it is necessary to modify LLDPE with the incorporation of nanofillers to get improved mechanical properties, flame retardancy as well thermal stability.

Some of the properties of the polyethylene, as specified by the manufacturer:

- Density $23{ }^{\circ} \mathrm{C}: 921 \mathrm{~kg} / \mathrm{m}^{3}$

- Melt flow rate $\left(190^{\circ} \mathrm{C} ; 2,16 \mathrm{~kg}\right): 0.28 \mathrm{~g} / 10 \mathrm{~min}$

- Tensile strength at break: $21 \mathrm{MPa}$

- Tensile strain at break: $360 \%$

- Tensile modulus: $220 \mathrm{MPa}$

- Vicat softening temperature: $93{ }^{\circ} \mathrm{C}$

- Shore D hardness $15 \mathrm{~s}: 50 \mathrm{ShD}$

The material LDPE was modified by Halloysite nanotubes (HNT). Halloysite is a naturally occurring member of the kaolin family of aluminosilicate clays. Halloysite can occur in several structures but predominantly exists as a tubular structure believed to be the result of hydrothermal alteration, or surface weathering of other aluminosilicate minerals [4, 6]. Halloysite nanotubes (HNTTM) do not require large amounts of chemical modification or complex chemical processes such as intercalation and exfoliation in order to produce stable nanoparticle clay dispersions in the melt. This makes it possible to obtain performance improvements without the complexity and processing cost associated with platy clays [14]. Halloysite nanotubes (HNT), by Sigma-Aldrich company, in the form of powder of the grain diameter from 30 to $70 \mathrm{~nm}$ and length 1-3 $\mu \mathrm{m}$, specific surface $64 \mathrm{~m}^{2} / \mathrm{g}$ and density $2530 \mathrm{~kg} / \mathrm{m}^{3}$ were used as filler.

Polyethylene grafted with maleic anhydride (PE-graft-MA), by Sigma-Aldrich Company, as a compatibility factor was used. Its melt temperature was $105^{\circ} \mathrm{C}$ and density $920 \mathrm{~kg} / \mathrm{m}^{2}$.

Material for experiments was blended at the three volume concentrations of 2,4 and $6 \mathrm{wt} \%$ of HNT within LDPE matrix and volume concentration of $5 \mathrm{wt} \%$ of compatibility factor in LDPE polymer.

\section{Methods}

Studies of selected mechanical properties of the moldings obtained with the change of HNT amount in LDPE matrix include measurements of Young's modulus, tensile strength $\sigma_{\mathrm{M}}$, strain at strength $\varepsilon_{\mathrm{M}}$, impact strength $\mathrm{a}_{\mathrm{CN}}$, hardness $\mathrm{ShD}$.

Tension testing in the static tension test of the obtained injection moulds with various amount of filler in the form of standardized specimens used in strength testing was conducted using a standard testing machine manufactured by TIRA GmbH (symbol TIRAtest 2300). Testing of obtained polyethylene specimens was conducted according to EN ISO 527-1:2012 standard; the accuracy of the test was $1 \mathrm{~N}$, and the speed of tension was $100 \mathrm{~mm} / \mathrm{min}$., temperature at testing in the laboratory was $22{ }^{\circ} \mathrm{C}$. The results are an arithmetic mean of five measurements.

The hardness testing was conducted according to the hardness measurement procedure described in the EN ISO 868:2005 standard. Plastics and ebonite - determining hardness using interference. Using a hardness testing machine (Shore method). Five hardness measurements were made on each 
specimen and the final result is an arithmetic mean of these measurements. Hardness tester Mitutoyo HardmaticHH-300 was used for hardness measurements testing.

The Charpy impact strength test was performed according to EN ISO 179-1:2010 Plastics Determination of Charpy impact properties - Part 1: Non-instrumented impact test. The results of impact strength are an arithmetic mean of ten measurements according to standard. Specimens dimensions for testing: specimen types 1; length: $\ell=80 \pm 2 \mathrm{~mm}$; width: $b=10.0 \pm 0.2 \mathrm{~mm}$; thickness: $\mathrm{h}=4.0 \pm 0.2 \mathrm{~mm}$; notch: type $\mathrm{C}$ (notch radius $\mathrm{r}_{\mathrm{N}}=0.10 \mathrm{~mm} \pm 0.02 \mathrm{~mm}$ ).

\section{Results and Discussion}

Strength test results for obtained polyethylene specimens are presented graphically as a plots of the mass content of the nanofiller HNT with the addition $(5 \%)$ of a compatibilizing agent as a function of the following variables: Young's modulus $E$, tensile strength $\sigma_{M}$, tensile strain at strength $\varepsilon_{\mathrm{M}}$. The figures below show the relationships between the mass content of the nanofiller HNT and the following parameters Young's modulus E (Fig.3), tensile strength $\sigma_{\mathrm{m}}$ (Fig.4), tensile strain at strength $\varepsilon_{\mathrm{m}}$ ( Fig.5) for the injection molded specimens obtained in the experiment.

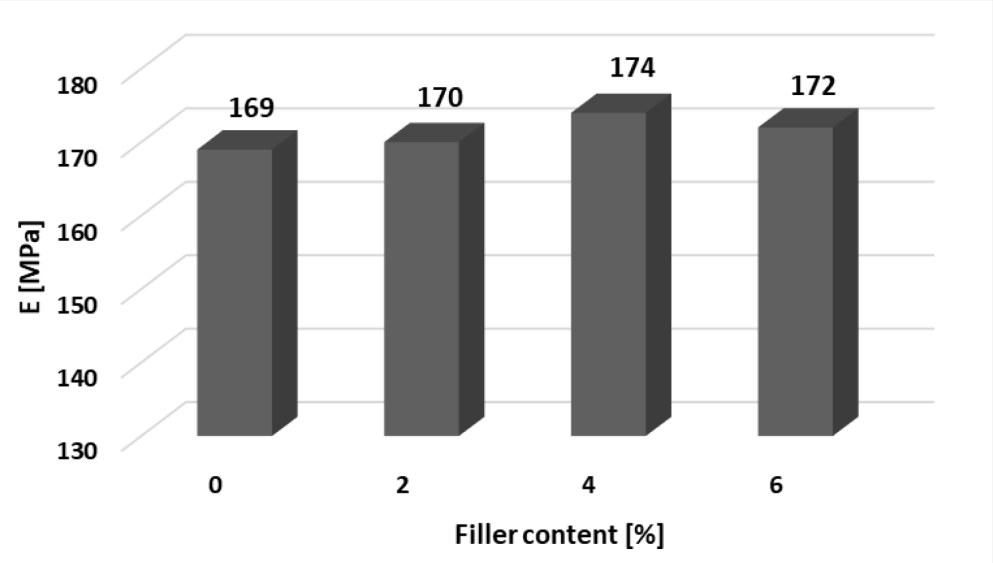

Fig. 3 The relationship between Young's modulus and the mass content of the nanofiller with the addition (5\%) of a compatibilizing agent

As it is shown on Fig. 3 Young's modulus has the similar dependence on HNT content in the nanocomposite based on LDPE; with the increase of HNT content and compatibility factor, Young's modulus increases. Injection molding of LDPE with various content HNT and 5\% PEgraft-MA resulted in increase in Young's modulus (Fig. 3), the value of which increased from $169 \mathrm{MPa}$ to $174 \mathrm{MPa}$ compared to the Young's modulus of the LDPE material, that is by more than $3 \%$, which was close to a potential error. The largest an increase in the Young's modulus (5 MPa) was measured for LDPE / 4\% HNT.

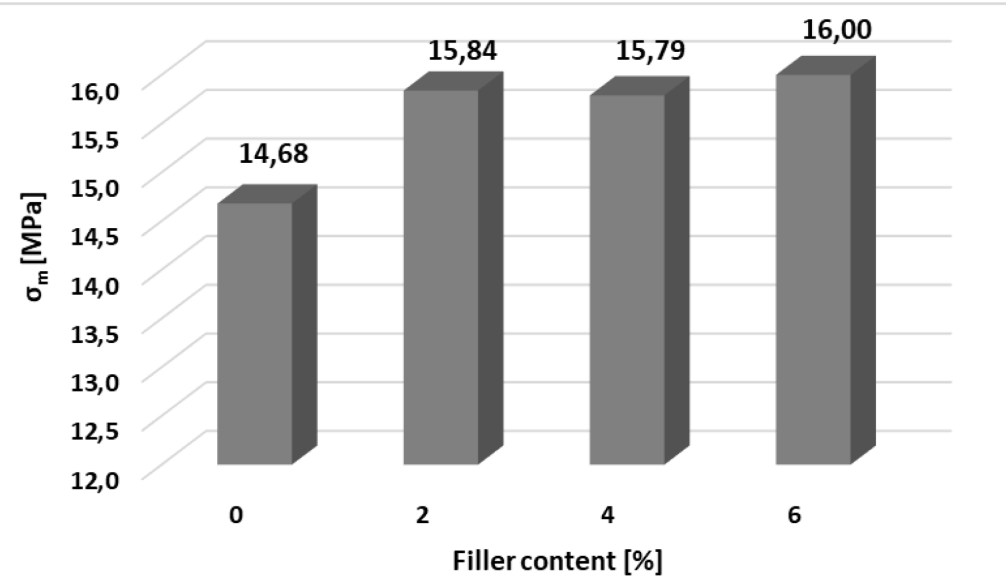

Fig. 4 The relationship between tensile strength and the mass content of the nanofiller with the addition $(5 \%)$ of a compatibilizing agent 


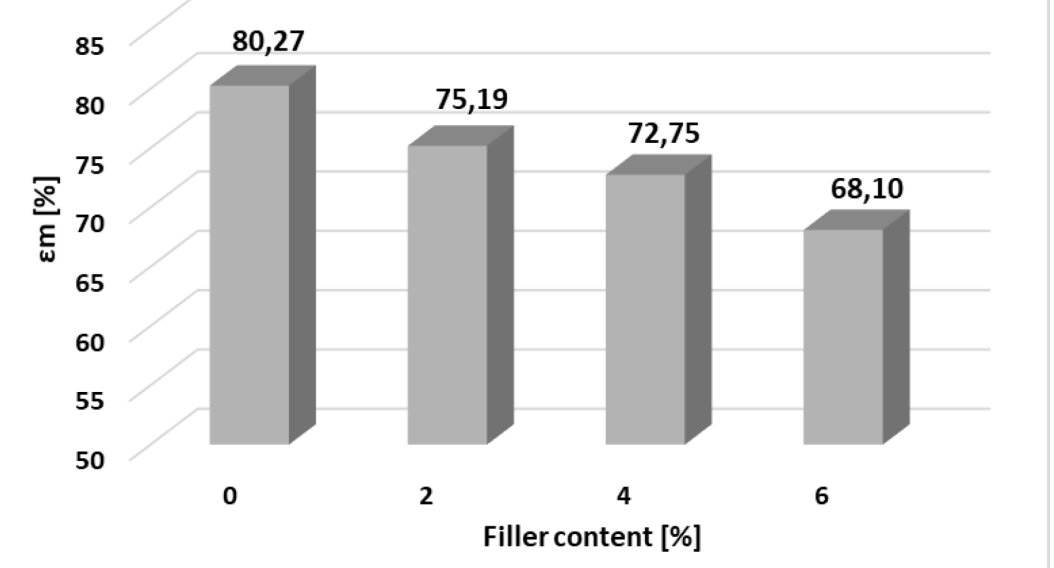

Fig. 5 The relationship between strain at strength and the mass content of the nanofiller with the addition (5\%) of a compatibilizing agent

Figure 4 presents the relationship between tensile strength and the mass content of the HNT in the matrix LDPE material with the addition (5\%) of a compatibilizing agent. Based on these results it can be concluded that the highest tensile strength was measured for the material LDPE filled $6 \%$ HNT (16 MPa) and lowest tensile strength was measured for the material LDPE filled 4\% HNT (15.79MPa). Tensile strength at HNT content of $2 \mathrm{wt} \%$ and $5 \%$ PE-graft-MA it is higher by $7.9 \%$ compared with the LDPE material and at HNT content of $6 \mathrm{wt} \%$ and $5 \%$ PE-graft-MA is higher by $9.0 \%$ compared with the pure LDPE material. The difference between the measured values of the tensile strength $\left(\sigma_{\mathrm{m}}\right)$ was minimal. The value tensile strength was increased by adding the filler content into the LDPE material.

The relationship between strain at strength and the mass content of the nanofiller with the addition (5\%) of a compatibilizing agent is shown on Fig.5. Based on strain at strength results it can be concluded that the highest strain at strength was measured for the material LDPE $(80.27 \%)$ and lowest strain at strength value was measured for the material LDPE with $6 \% \mathrm{HNT}$ and 5\% PE-graftMA (68.10\%). Strain at strength at HNT content of $2 \mathrm{wt} \%$ and $5 \%$ PE-graft-MA it is smaller by $6.3 \%$ compared with the LDPE material and at HNT content of $6 \mathrm{wt} \%$ and $5 \%$ PE-graft-MA is smaller by $15.2 \%$ compared with the LDPE material. The value strain at strength was decreased by adding the filler (HNT) and compatibility factor (PE-graft-MA) into the LDPE material.

The breach of tested materials (the LDPE material and material with nanofiller) were observed by digital microscope Keyence VHX-500 and are shown in Fig.6 and Fig.7. The rupture of the material is non-solid with visible scraps on the surface of violation. These were caused by the interaction of spreading cracks during the test.
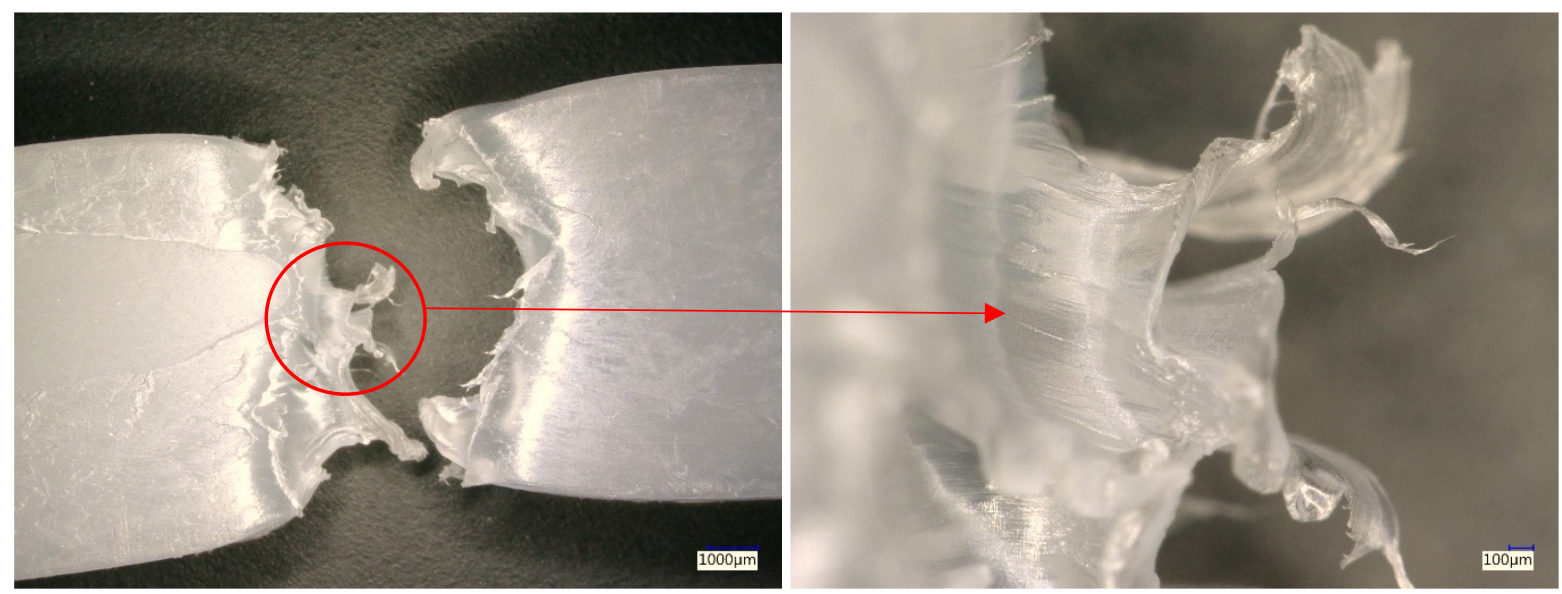

Fig. 6 Tensile fracture sample of low-density polyethylene (LDPE) 

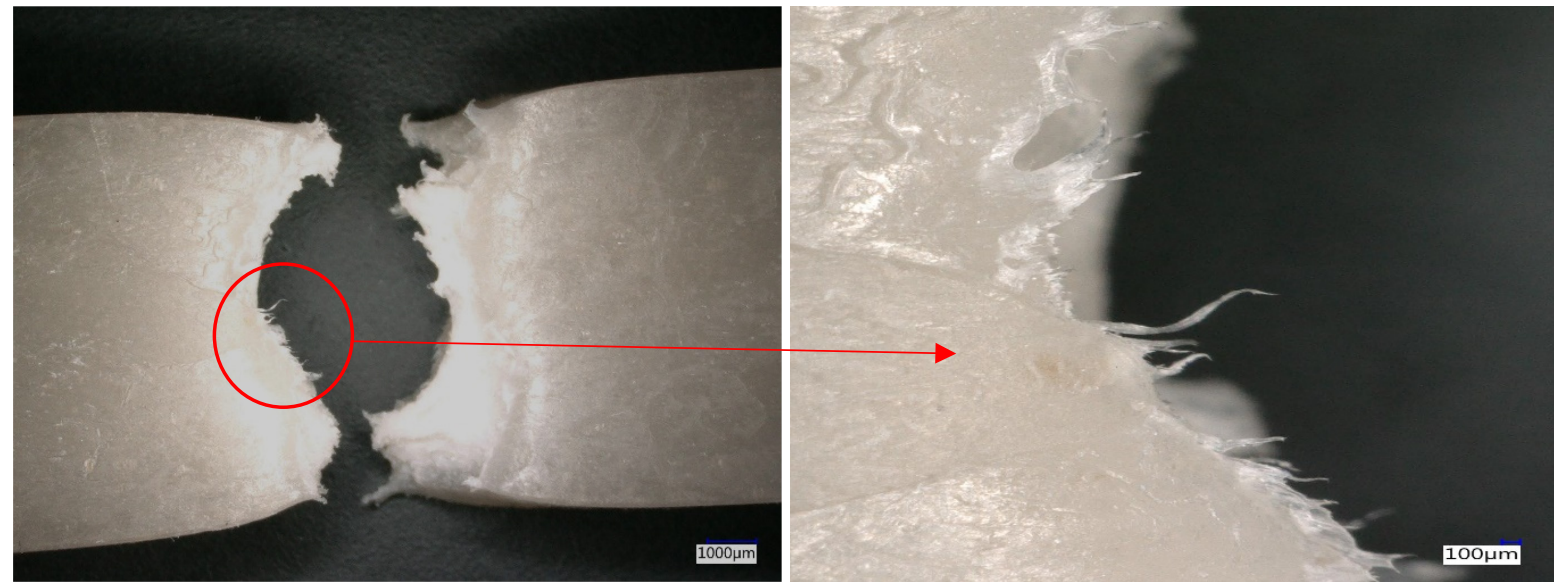

Fig. 7 Tensile fracture sample of low-density polyethylene (LDPE) and Halloysite nanotubes (6wt $\%$ HNT) as a nanofiller

In Fig. 6 and Fig. 7 a ductile fracture is observed which is characterized by the stretching of the material with respect to the fibrous character of the polymers. It is a response to an active tensile stress.

Figure 8 presents the relationship between Shore hardness and the mass content of the HNT in the matrix LDPE material. Based on these results it can be concluded that the highest Shore hardness value was measurement for the LDPE material (51.3 ShD). After addition of 2 to $6 \mathrm{wt} \%$ nanofillers and 5\% PE-graft-MA to the LDPE material, the hardness value was reduced. For example hardness value 49.8 ShD was measurement for the material LDPE with 4\% HNT and 5\% PE-graft-MA. Shore hardness at HNT content of $2 \mathrm{wt} \%$ and $5 \%$ PE-graft-MA it is smaller by $1.16 \%$ compared with the LDPE material, at HNT content of $4 \mathrm{wt} \%$ and $5 \%$ PE-graft-MA is smaller by $2.9 \%$ compared with the LDPE material and at HNT content of $6 \mathrm{wt} \%$ and $5 \%$ PE-graft-MA is smaller by $2.3 \%$ compared with the LDPE material. The hardness was decreased by adding the nanofiller and the compatibility factor PE-graft-MA into the LDPE material. The difference between the measured of the hardness values was minimal.

The relationship between Charpy impact strength and the mass content of the nanofiller HNT with the addition of a compatibilizing agent is shown in Fig. 9.

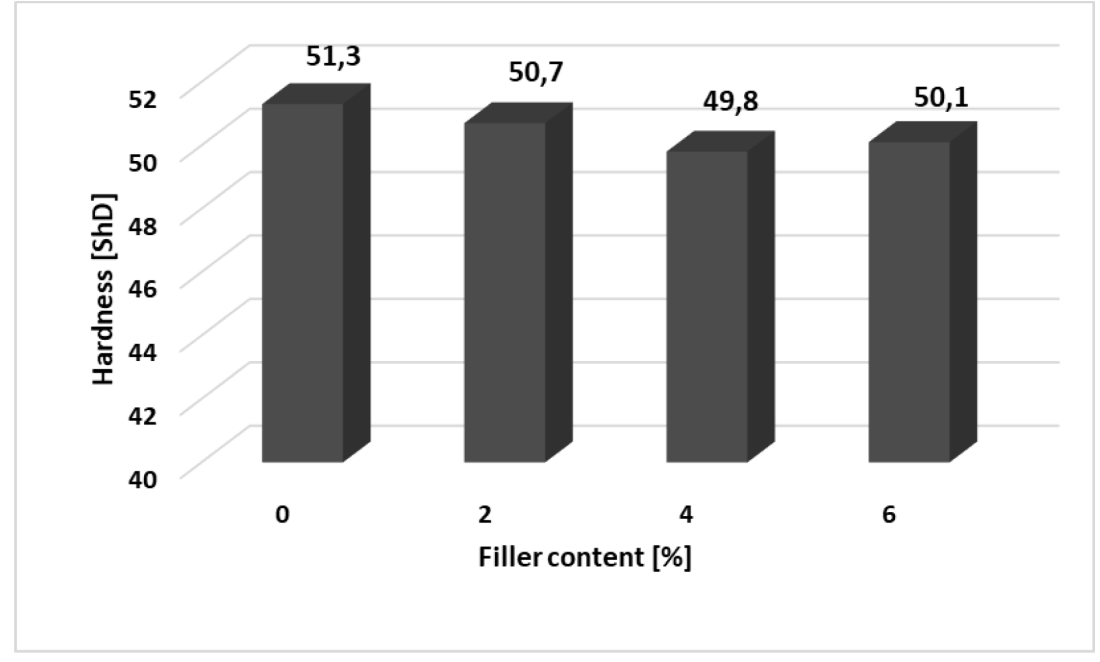

Fig. 8 The relationship between hardness and the mass content of the nanofiller with the addition $(5 \%)$ of a compatibilizing agent 


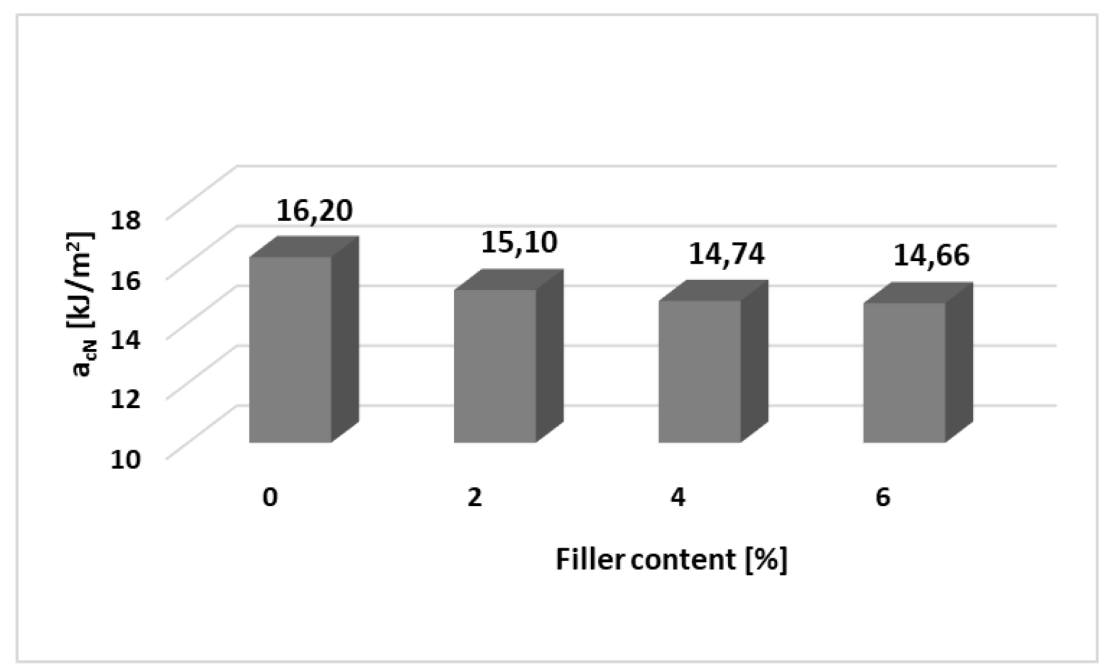

Fig. 9 The relationship between impact strength and the mass content of the nanofiller with the addition (5\%) of a compatibilizing agent

Based on these results it can be say that the highest impact strength value was measurement for the material pure LDPE $\left(16.20 \mathrm{~kJ} / \mathrm{m}^{2}\right)$. After addition of 2 to $6 \mathrm{wt} \%$ nanofillers and $5 \%$ PE-graftMA to the LDPE material, the impact strength values of tested materials were decreased. Impact strength at material LDPE with HNT content of $2 \mathrm{wt} \%$ and $5 \%$ PE-graft-MA was measured smaller by $6.8 \%$ compared with the LDPE material. Impact strength at material LDPE with HNT content of $6 \mathrm{wt} \%$ and $5 \%$ PE-graft-MA is smaller by $9.5 \%$ compared with the LDPE material.

\section{Conclusions}

This study investigated the influence of Halloysite nanotubes (HNT) and PE-graft-MA within a Low- Density Polyethylene (LDPE) matrix on the mechanical properties. The mechanical properties of specimens made by the injection molded were determined. The results of the tests conducted in this study on the effect of the mass content of the nanofiller $(2,4,6 \mathrm{wt} \%)$ with the addition (5\%) of a compatibility agent demonstrated that the amount filler and compatibility factor PE-graft-MA has minimum effect on the mechanical properties of the polymer. The mechanical properties of the polyethylene (Young's modulus, tensile stress, strain at strength) determined in a static tensile strength test were changed by adding filler. Young's modulus was increased by addition of compatibility factor PE-graft-MA and fillers. The tensile strength was increased by adding the filler and PE-graft-MA and strain at strength was decreased by adding the fillers and PE-graft-MA into the LDPE material. It has been established that the Young's modulus, tensile stress, strain at strength did not change too greatly. The hardness of the tested materials remained almost constant over the test but showed a tendency to decrease. Added of the filler into LDPE material had no significant effect on hardness of tested materials. The largest deterioration of the investigated properties was observed for the tested material by the Charpy impact test where the impact strength values of tested materials were decreased about $9.5 \%$.

\section{Acknowledgement}

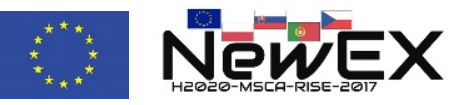

This project has received funding from the European Union's Horizon 2020 research and innovation programme under the Marie Skłodowska-Curie grant agreement No 734205 - H2020-MSCA-RISE-2017. 


\section{References}

[1] B. Duleba, F. Greškovič, Application of clay based nanofillers at polymers nanocomposites, In: Technological and design aspects of extrusion and injection moulding of thermoplastic polymer composites and nanocomposites. Volume I., Lvov.2013, 127-139.

[2] A.K Haghi, G.E Zaikov, Update on Nanofillers in Nanocomposites: From Introduction to Application, Smithers Rapra Technology Ltd, UK, 2013.

[3] Ch. Y. Chee, N. L. Song, L.Ch. Abdullah, T. S. Y. Choong, A. Ibrahim, and T. R. Chantara, Characterization of Mechanical Properties: Low-Density Polyethylene Nanocomposite Using Nanoalumina Particle as Filler, Journal of Nanomaterials, 2012 (2012) 6 pages.

[4] E. Joussein, S. Petit, G. Churchman, B. Theng, D. Righi and B. Delvaux, Halloysite clay minerals - a review, Clay Minerals 40 (2005) 383-426.

[5] L. Dulebova, T. Garbacz, V. Krasinskyi and B. Duleba, The influence of modifying HDPE on properties of the surface, Materials Science Forum, 818 (2015)101-104.

[6] B. Theng, M. Russell, G. Churchman and R. Parfitt, Surface properties of allophane, halloysite, and imogolite, Clays and Clay Minerals 30 (1982)143-149.

[7] J. Jancar, Review of the role of the interphase in the control of composite performance on micro- and nano-length scales. Journal of Materials Science, 43 (2008) 6747-6757.

[8] L.S. Sutherland, R.A. Shenoi and S.M. Lewis, Size and scale effects in composites: I. Literature review. Composites Science and Technology, 59(1999) 209 - 220.

[9] P. C. Ma, N.A. Siddiqui, G. Marom and J. K. Kim, Dispersion and functionalization of carbon nanotubes for polymer-based nanocomposites: A review. Composites Part A: Applied Science and Manufacturing, 41 (2010)1345-1367.

[10] A. Lagashetty, A. Venkataraman, Polymer nanocomposites, Resonance, (2005) 49-60.

[11] Y. C. Ching, I. I. Yaacob, Effect of polyurethane/nanosilica composites coating on thermomechanical properties of polyethylene film, Materials Technology, 27 (2012) 113-115.

[12] D. Pedrazzoli, A. Pegoretti, R. Thomann, J. Kristof and J. Karger-Kocsis, Toughening Linear Low-Density Polyethylene With Halloysite Nanotubes, Polymer Composites, 36 (2015) 869883.

[13] E. James, Polymer Data Handbook, Oxford University Press, New York (1999).

[14] V.P. Singh, K.K. Vimal, G.S. Kapur, Sh.Sharma and V. Choudhary, High-density polyethylene/halloysite nanocomposites: morphology and rheological behaviour under extensional and shear flow, J Polym Res (2016) 23: 43. 